Article

\title{
An Innovative Method for Project Transaction Mode Design Based on Case-Based Reasoning: A Chinese Case Study
}

\author{
Jiyong Ding ${ }^{1,2} \mathbb{D}$, Jianyao Jia ${ }^{3, *}$, Chenhao Jin ${ }^{1,2}$ and Na Wang ${ }^{1}$ \\ 1 Institute of Engineering Management, Business School of Hohai University, Nanjing 211100, China; \\ jyding@hhu.edu.cn (J.D.); cjin@hhu.edu.cn (C.J.); wangnacg@hhu.edu.cn (N.W.) \\ 2 Jiangsu Provincial Collaborative Innovation Center of World Water Valley and Water Ecological Civilization, \\ Nanjing 211100, China \\ 3 School of Economics and Management, Tongji University, Shanghai 200092, China \\ * Correspondence: jianyaoJ@tongji.edu.cn; Tel.: +86-151-5068-7217
}

Received: 19 September 2018; Accepted: 6 November 2018; Published: 9 November 2018

check for updates

\begin{abstract}
Aiming at the design of a project transaction mode, the case-based reasoning (CBR) method is used as a methodology to build a case-based reasoning system based on project performance predictions. Thirty-four cases are initially selected for the practical application. Based on the classical CBR, the performance forecast is added, an improved continuous variable interpolation scoring method is proposed, and three types of manual revision methods are proposed: owner's preference for the project transaction mode, extreme value, and secondary learning. The innovative method is verified with Nanjing HF Project as an example, and the results show that the case-based reasoning system can optimize the selection and design of the project transaction mode, providing a certain guarantee for project performance and facilitating the transfer of construction experience and knowledge within the construction industry.
\end{abstract}

Keywords: project transaction mode; case-based reasoning; performance prediction

\section{Introduction}

The project delivery system/method (PDS/PDM) describes how project participants are organized to interact with each other, transforming the owner's goals and objectives into finished facilities [1]. As one of the critical factors in project success, the PDS not only affects the innovation in the construction industry, but also has a significant influence on project quality, schedule, cost, and contract management [2-4]. Once the project delivery method is selected at the beginning of the project, it is challenging and expensive for the owner to change the PDS during the project implementation process [5]. Therefore, the best way to design a project delivery method that matches the characteristics of a specific project is an important issue worthy of study.

From the perspective of the whole transaction process, the project delivery method is only a core part the transaction system, not the entirety of it. It does not determine how to choose the transaction subject in the transaction process, how the owner manages and supervises the project, and how the payment will be made, which are also important issues for project success, with a significant impact on both project performance and sustainability. For example, the strategy for selecting a design-builder and a construction contractor may be quite different. In addition, if the selected contractor is not competent for the project task, or the two contract parties have significant disagreements on the pricing issue, the project will inevitably not be completed on time. Therefore, it is necessary to consider these issues under the same framework to better ensure the project performance and project sustainability 
and reflect the complete transaction process as well as the transaction relationship between the two parties. From the perspective of the transaction, all these issues are essential during the transaction process, and we need to find the solutions to these issues when designing the transaction system. Based on the above discussion, this study incorporates these related issues into the project transaction mode (PTM) considering the integrity of the transaction process, which also reflects the application of system engineering in project management.

The project transaction mode system includes four sub-modules: the project delivery method, contract type (payment method), the owner's management method, and the project procurement method (contractor selection method), with the specific logic structure shown in Figure 1. The project delivery methods mainly include design-bid-build (DBB), design-build (DB), engineering procurement construction (EPC), integrated project delivery (IPD), and construction management at risk (CMR), etc. The contract type mainly includes the unit price contract, lump sum contract, and cost reimbursement contract. The owner's management methods mainly include autonomous management (self-management), joint management, and commissioned agency such as agent construction system, project management (PM) and construction management at risk (CMA), etc. The project procurement method includes open tendering, invited tendering, competitive negotiation, and direct contracting, etc. Obviously, if the four sub-modules are not designed under the same framework, it is very likely that the two parties will have intersections and contradictions on rights and responsibilities. This situation may lead to numerous conflicts between the two parties, which will damage the project performance. Therefore, the overall design is necessary for the PTM system. However, even if these sub-modules are the same, there are differences within each sub-module. For example, although the same lump sum contract is adopted, different payment terms and different payment times still have various impacts on project performance.

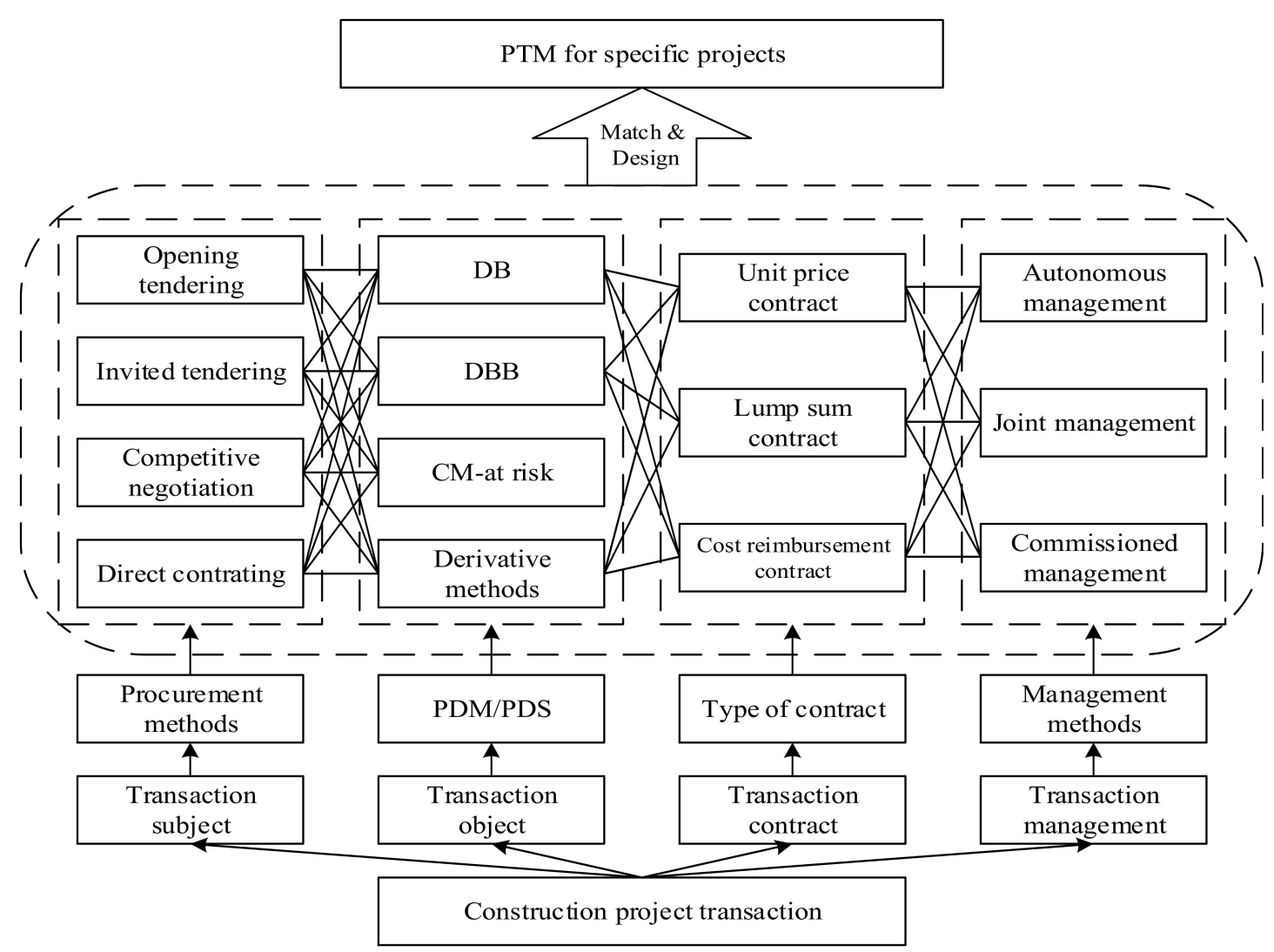

Figure 1. Basic elements of the project transition mode. PTM: project transaction mode; DB: design-build; DBB: design-bid-build; CM: construction management; PDM/PDS: project delivery method/system. 
It should be pointed out that Article 3 in the Bidding Law of People's Republic of China stipulates the scope of the projects in which the contractors must be determined through bidding. The National Development and Reform Commission's Decree No. 16 in 2018 also issued the corresponding Provisions for Construction Projects That Must Be Bidded Upon. These laws and regulations mostly limit the choice of procurement methods by the owner. Consequently, this study has not included the project procurement method, but the procurement method is still listed together with the project delivery method, contract type, and owners' management method to reflect the integrity of the project transaction mode.

\section{Literature Review}

\subsection{Decision-Making Method for Project Transaction Mode}

Many scholars have conducted relevant research on the selection/design of project delivery methods. Alhazmi et al. [6] applied the analytical hierarchy process (AHP) method to the selection of project delivery methods. Later, many scholars made improvements to the original AHP method. Mafakheri et al. [7] used rough set theory to construct an AHP decision model for PDM selection under uncertain conditions; Khanzdi et al. [8] combined fuzzy decision and AHP and proposed the fuzzy multi-attribute group decision-making model for the selection of the project delivery method. Both Teak et al. [9] and Lu et al. [10] considered the fact that the decision-making factors affecting the project delivery method are mutually influenced and interrelated and developed the analytic network process (ANP) model on the basis of AHP for PDS decision.

AHP can be used to select a reasonable project delivery method to a certain extent. However, it is highly dependent on experts' subjective opinions. Many decision-making methods and models have been developed to overcome this shortcoming. Ling et al. [11] developed an artificial neural network (ANN) method to construct a nonlinear predictive model and predicted the performance of DB projects. Based on previous achievements, Chen [12] firstly used the DEA-BND (Data Envelopment Analysis-Bound Variable) model to test and correct the indicator value, and then fed the obtained data to the ANN model for training purposes, and finally obtained the performance of the target project with a reasonable project delivery method. Touran et al. [13] and Abkarian et al. [14] regarded the traditional project delivery method (DBB) as a reference and considered other project delivery methods (DB, CM-at-risk, etc.) as alternatives. Through case analysis, the project performance of different delivery methods was compared and used as a basis of making the delivery decisions for new projects. Luo et al. [15] developed a project delivery decision model based on simplified neutrosophic linguistic preference relations. In this method, experts only need to provide their preference information, which can reduce subjectivity significantly.

In addition, the case-based reasoning (CBR) method is also applied in some research on the PDM selection problem. Riberiro [16] proposed a PDM selection model framework based on the CBR method. Luu et al. [17] established a PDM selection system framework with the combination of CBR and fuzzy value attributes. Yousang et al. [18] combined the CBR method with the DT method and used the DT method to further weaken the subjectivity of PDM selection. Meng et al. [19] improved the CBR method and established a framework for PDS selection based on relational case-based reasoning. However, due to the difficulties in data collection, empirical study has not been implemented to verify this framework.

From the literature review above, it can be seen that the current research on the decision-making for project delivery methods mostly starts with the factor analysis of the PDM selection problem [20], which is mainly divided into the expert model method and case study method. Both the expert model method and the case study method rely on the learning of experience, which also reflects the lack of strong theoretical models and complete domain knowledge in the decision-making field of project transaction modes. In addition, most of the existing studies are limited to the selection of project delivery methods, while the three important factors that affect the successful operation of the 
PDM have not been considered: the contract type, the owner's management method, and project procurement method. The selection of the above three aspects has some path dependence on the project delivery method [21]. Therefore, it is necessary to consider the contract type, the owner's management method, the project procurement method and project delivery method in the same conceptual framework, namely the project transaction mode [21], and then study the overall selection or design of the project transaction mode. Research and practice show that the selection or design of the project transaction mode of a construction project is a critical factor for project success. The selection or design of a project transaction mode is a multi-objective optimization problem [22], not just a simple selection or combination of existing methods.

\subsection{Project Transaction Mode and Project Performance}

Existing research has focused on the comparison of performance indicators between different delivery methods. Konchar et al. [23] and Love et al. [24] conducted relatively early systematic research in this area, but they drew opposite conclusions regarding cost performance. Furthermore, Love et al. pointed out that DB's advantages are mainly due to the reduced uncertainty for the owner, which is more conducive to project control. However, their research did not distinguish between different project categories. Later, some scholars paid attention to this research gap and conducted further studies. Rojas et al. [25] focused on public school projects and found that the total cost growth rate in a CM project is higher than a DBB project, although the cost increase caused by the change of a CM project is small. Carpenter et al. [26] also concentrated on public school projects, with conclusions which were consistent with Rojas et al. concerning cost. Shretha et al. [27], through their research on university construction projects, concluded that DB projects have better schedule performance and fewer changes. Minchin et al. [28] paid attention to the performance research of road and bridge projects with different project delivery methods in Florida. It was concluded that DBB projects have more advantages in cost performance than DB projects, while the schedule performance under DBB is not as good as that under DB, with other performance indicators having no significant gaps between them. Park et al. [29] and Shretha et al. [30] reached conclusions consistent with Minchin et al. through the research on transportation construction projects and large-scale expressway projects. Tran et al. [31] were concerned about the differences between expressways with different investment. Their study found that DBB projects had an advantage in cost performance only in projects ranging from $\$ 50$ million to $\$ 100$ million, while DB projects showed better cost performance when the investment is between $\$ 10$ million and $\$ 50$ million. Shane et al. [4] collected 31 DB municipal water-related projects and 69 DBB municipal water-related projects. It was found that the schedule growth rate of the DB projects was only half of the DBB projects, and the cost of most DB projects could be controlled within the budget. Hale et al. [32] conducted research on military residential projects considering their similarity. The results showed that the performances of DB projects were better than that of the DBB projects in almost all indicators. Park et al. [33] focused on large-scale public housing projects, and their conclusions are consistent with the statistical analysis of the existing construction project performance literature made by Sullivan et al. [34]; namely, DB projects were superior in cost, schedule, quality, and efficiency. In addition, Love's research [35] on rework construction projects showed that there was no difference in cost performance between different delivery methods. Tran et al. [36] divided different projects into new projects, reconstruction projects, resurfacing restoration rehabilitation (3R) projects, intelligent transportation system-related projects and miscellaneous construction projects, and their research showed that $3 \mathrm{R}$ projects and miscellaneous projects which adopt DB had advantages in cost and schedule, and the construction intensity in new construction and reconstruction projects adopting DB was higher. According to the studies above, it can be concluded that no certain project delivery method has advantages in all aspects of performance. Different project delivery methods have applicability in construction projects of different scales, different types, and in different industries. Only with the appropriate one applicable to the project is it possible to produce better performance. 
At present, the research on the impact of the other three elements of project transaction modes on performance is relatively scarce. Seob et al. [37] believed that the contract type is one of the crucial factors affecting the project success since the two parties conduct the transaction on a contract basis. He collected the project data and empirically analyzed the cost, schedule, safety and change or reworking by different contract types. Xu et al. [38] theoretically explained the relationship between contract type and transaction cost. From the perspective of economics, Wang et al. [39] analyzed the cost of the owner's adoption of different management methods. It was concluded that PM should be adopted when the owner's project management ability is weak, and the experience is lacking. On the contrary, construction supervision is more reasonable. Dong et al. [40] emphasized that all project stakeholders should participate in safety management, but the responsibility of the owner is often vague. If a reasonable management method cannot be designed, the owner will not be able to participate in safety management appropriately. Regarding the procurement method of the project, the "Provisions for Construction Projects That Must Be Bidded Upon", issued by the National Development and Reform Commission of China, proposed that the purpose of the document is to improve work efficiency, reduce enterprise costs and prevent corruption. On the one hand, bidding introduces a procurement mechanism and reduces information asymmetry; on the other hand, transaction costs have to be paid for by the mechanisms that are formed, which are reflected in the cost of the project. At the same time, corruption prevention is often more important than cost reduction, especially in public projects. At present, it is rare to regard these elements of PTM as a whole and then to study the relationship between them and its impact on performance. Chen et al. [41] comprehensively considered the delivery method and contract type and found that the project cost overrun rate is the lowest in projects with design-build and the negotiated lump sum contract.

The latest DB policy issued by relevant departments of the Chinese government has clearly stated that the design-builder of the project has general responsibility for safe production at the construction site. This provision clarifies the subject of safety responsibility for the construction site under DB. For DBB projects, due to the large time span and involvement of multiple specialties, different contractors have different entry times, and their working interfaces are crossed and blurred, which often leads to the shirking of safety responsibilities. In fact, safety management is mainly based on prevention. When contractors push off each other, it often leads to problems such as insufficient safety investment, a lack of safety education and incomplete safety equipment, which are important hidden risks for safe production. Besides this, safety management requires the participation of all stakeholders, so there is a certain relationship between the owners' management method and safety performance. Therefore, in the current context of China, there is a certain relationship between the project transaction mode and safety performance.

\subsection{Case-Based Reasoning}

The case-based reasoning (CBR) method is an intra-field analogical reasoning method developed from artificial intelligence [42]. It has been widely applied in the research of construction management, including bidding quotation [43], resource estimation [44], schedule estimation [45], cost estimation [46], risk identification [47], team selection [48], and delivery method decision [16-18], etc. The prerequisite assumption of effective application of the CBR method is "similar problems have similar solutions", which means the first step is to find the case that is most similar to the current problem, and then use solutions of these cases as the initial solution to the current problem, and correct the initial solution until the solution of the current problem is obtained [49]. CBR method is also highly dependent on the rich experience of experts, and it is inevitable that certain people are subjective. However, the CBR method is particularly applicable to the decision-making environment without a strong theoretical model or complete domain knowledge, and highly dependent on experts' rich experience [50]. Furthermore, the decision of the project transaction mode has the characteristics of complexity, uncertainty, and ambiguity, etc. [51]. These factors determine that the CBR method is particularly appropriate for the design or selection of the project transaction mode. 
Given the above research, this paper integrates the project delivery method, contract type, the owner's management method, and the project procurement method into the project transaction mode framework. This paper uses a case-based reasoning method to conduct decision-making research on the project transaction mode design. This research aims to provide a novel methodology to improve the current decision-making process and make scientific and rational design decisions for the project transaction mode to ensure the success of construction projects. In terms of research content and research methods, we combine three major concepts including system, history, and design. Specifically, the project transaction mode incorporates the elements of the transaction process into the same framework, which is the embodiment of system thinking, while the decision-making based on previous successful cases reflects historical thinking, and the continuous accumulation of successful cases creates conditions for continuous decision-making improvement. Any element of the project transaction mode is a collection of a series of terms, so the transaction mode of each project needs to be systematically designed based on the actual situation and the previous successful cases. The technical roadmap of this research is shown in Figure 2.

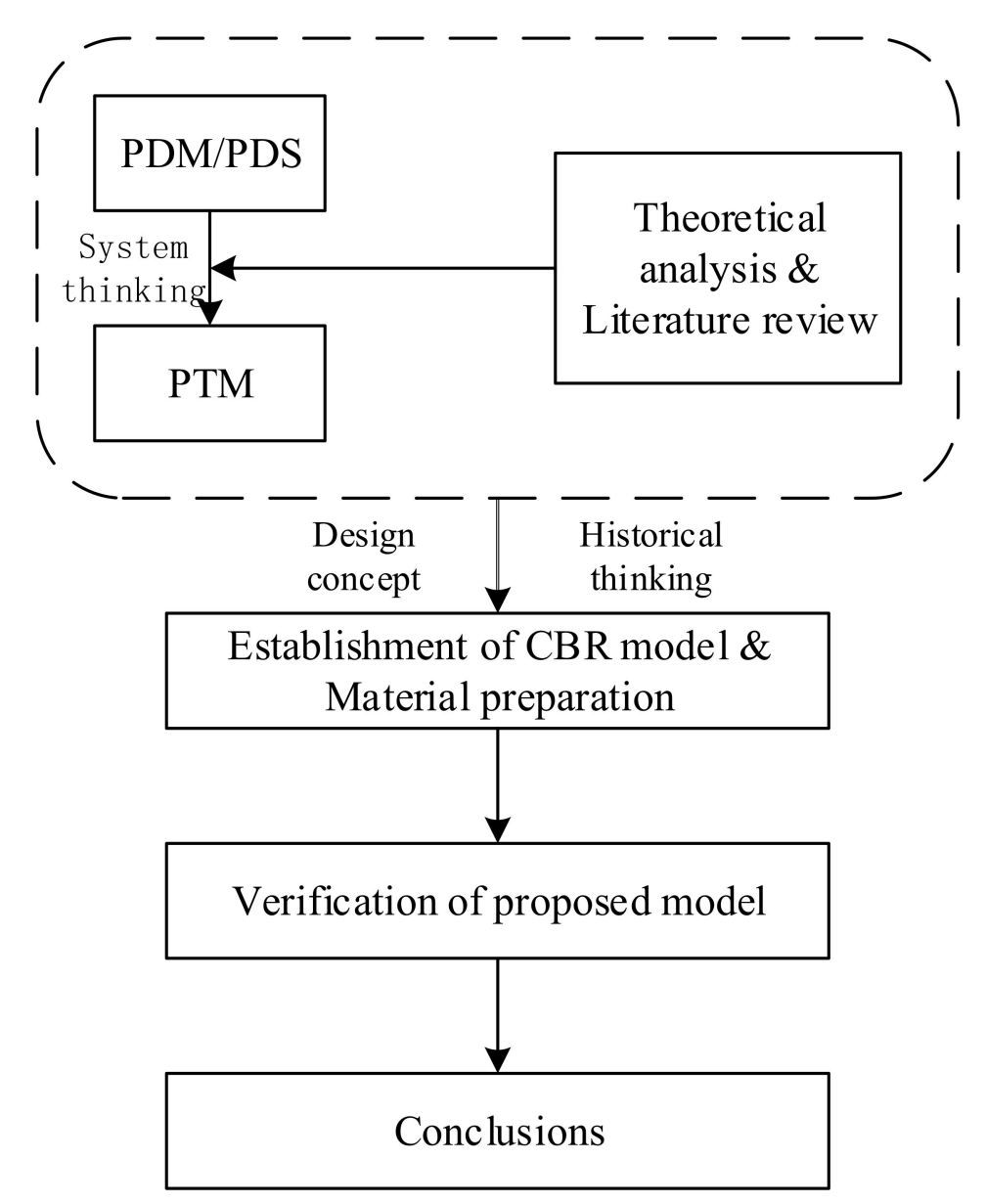

Figure 2. Technical roadmap of this research.

\section{Materials and Methods}

\subsection{The Overall Framework for the Project Transaction Mode Design}

Based on the traditional case-based reasoning process, with project performance as orientation, and the targeted optimization of each procedure, the overall framework of the CBR-based project transaction mode design can be obtained, as shown in Figure 3.

As shown in Figure 1, the framework consists of five basic steps: (1) the establishment of a case library; (2) case retrieval; (3) case reuse; (4) case revision; and (5) performance prediction. Compared 
with the traditional CBR process, the "performance prediction" procedure is added. That is to say, using this method to design the transaction mode can predict the performance of the project. Compared with the traditional method based only on influence factors, this method is more direct and performance-oriented and puts more emphasis on the final impact of the project results. In this way, this method is conducive to the scientific decision-making of a transaction mode to improve project performance.

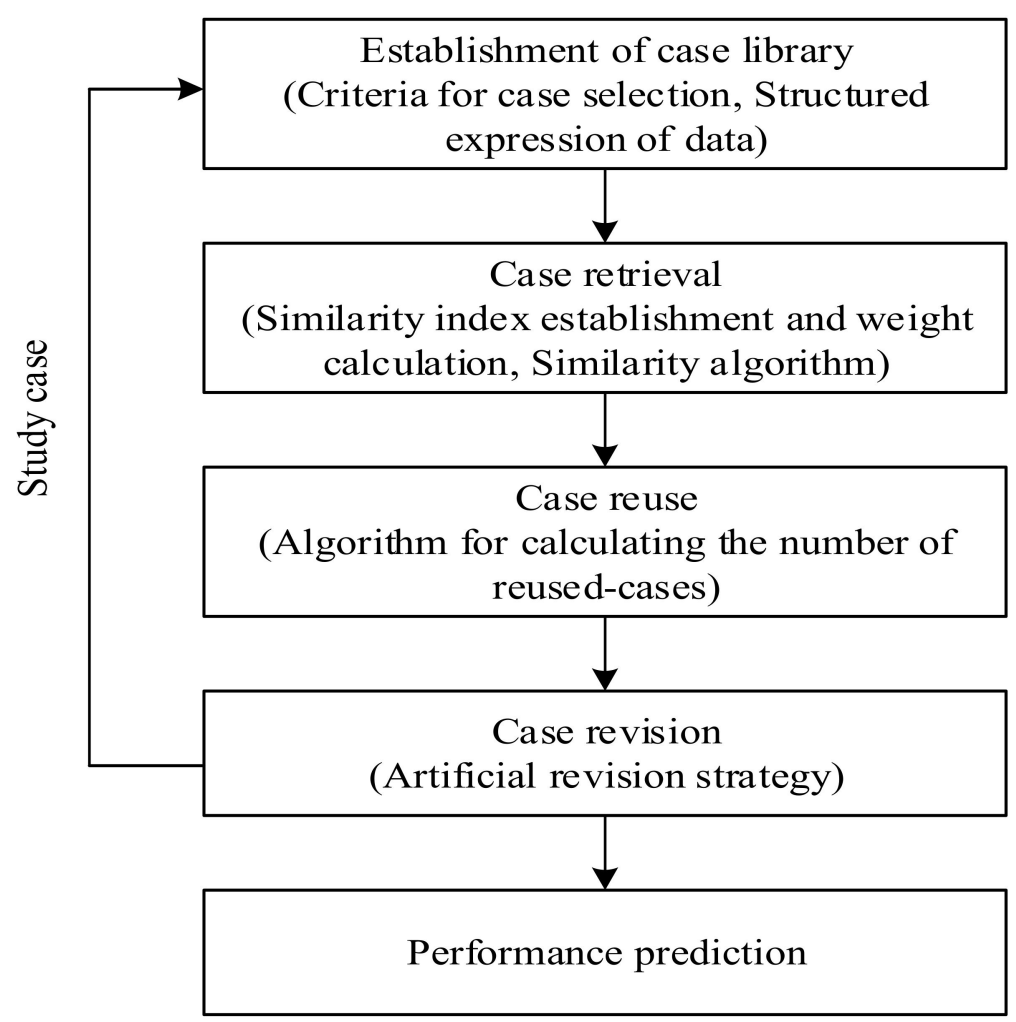

Figure 3. The overall design framework of project transition mode based on CBR.

\subsection{Establishment of Case Library}

\subsubsection{Criteria for Case Selection}

Selecting suitable cases and building the case library is an essential step in applying CBR methods to solve problems. The case study of this research was obtained mainly through questionnaire surveys and in-person interviews. After feedback information was collected, data were further processed and organized based on information from bidding websites and related literature documents. The following criteria were set to screen the collected cases to put in use into the case library: (1) The construction project must be located in the People's Republic of China. Different countries perform project transaction modes with different national characteristics. This criterion mainly took into account the differences in the policies and regulations of construction projects in different countries to ensure the case comparability of this research; (2) The construction project must be started after 2005, since the Code for management of engineering contracting projects was issued in China in 2005. This criterion was set to consider the development of the transaction mode evolves in China over time, and at a different period, the government has various policy orientations and influences on the transaction mode of construction projects. This criterion was also used to weaken the impact from the variance of social, economic systems on the comparability of these cases; (3) The comprehensive performance of the construction project in four aspects (including schedule, quality, cost, and safety [52,53]) must reach 3.75 points in a 5-point scale (the reason why 3.75 is selected as the cut-off point is that the performance of the selected case is higher than the average (3.61 in this research), and the case that 
finally enters the case library must reach a certain number; (4) The information about the influence factors of the project transaction mode must be complete.

\subsubsection{Structured Expression of Data}

The data of the cases are stored in the unit of a case, and each unit includes three parts: basic information, the influence factors' value of the transaction mode, and project performance. The basic information of the project is in the form of text, and the other two parts are structured information in digit numbers. Considering the small amount of data and the structured characteristics, an Excel spreadsheet was used to store the data of the case library and perform the tasks of data processing.

\subsection{Case Retrieval}

\subsubsection{Similarity Index Establishment and Weight Calculation}

The establishment of a case similarity index is a key step in the CBR system. In this research, the similarity index system is built based on the influence factors of the project transaction mode. As explained in the Introduction, the procurement method of projects in China is mainly influenced by the government regulations, and so the discussion here does not include the project procurement method, but in order to reflect the integrity of the transaction mode, they are listed together. A higher similarity of the influencing factors of the transaction mode results in higher consistency in the design of the transaction mode. In the previous research work, the authors' research team has developed the influencing index system and its corresponding weighting system for the project transaction mode [54]. This research also adopts the above methods. What should be noted is that the project procurement method is excluded because the Chinese government's regulations have a significant influence on its selection.

From the perspectives of the transaction, the influence factors of project transaction modes can be classified into three aspects: the transaction subject, transaction object, and transaction environment. A pilot study was implemented by sending questionnaires to experts to identify influence factors in each aspect. From the exploratory analysis of survey recovery, 14 influence factors were identified: project economic attributes, project size, project complexity, disturbances among subprojects, investment control requirements, duration control requirements, quality control requirements, construction management capabilities of the owner, risk appetite, owner's preferences for a project delivery method, land acquisition and resettlement, construction site conditions, national and local policies and regulations, and the construction market development level (the 14 factors correspond to questions 1-14 in the third part of the questionnaire). Then, the weights were calculated by the G1 algorithm, and the questionnaires of multiple experts were comprehensively weighted.

\subsubsection{Algorithm for Similarity Calculation}

In the survey, the questions about the similarity index are all single choice questions. The recovery data of the similarity index are divided into discrete variables and continuous variables. For continuous variables, the similarity is usually calculated by the classical interpolation algorithm which has excellent effects when the range of continuous variables is not too broad. With the increase of the scale, underestimated or overestimated phenomena start to appear, and the index similarity cannot be accurately measured. In order to deal with continuous variables with a broad range of variations, the classical interpolation algorithm can be logarithmically transposed for improvement. Three types of similarity algorithms are involved in this study: the three-level scoring system for discrete variables (Algorithm 1), the continuous variable interpolation scoring system (Algorithm 2), and the improved continuous variable interpolation scoring system (Algorithm 3), which are listed in Table 1 for details. 
Table 1. Three types of similarity algorithm.

\begin{tabular}{|c|c|c|c|}
\hline & Formula & Parameter Significance & $\begin{array}{c}\text { Applicable } \\
\text { Question Number }\end{array}$ \\
\hline Algorithm 1 & $I S=\left\{\begin{array}{cc}100, & I V_{T}-I V_{R}=0 \\
50, & \left|I V_{T}-I V_{R}\right|=1 \\
0, & \left|I V_{T}-I V_{R}\right|=2\end{array}\right.$ & \multirow{3}{*}{$\begin{array}{c}\text { IS: Similarity of index I } \\
I V_{T}: \text { Index value of the target case } \\
I V_{R}: \text { Index value of the alternative case } \\
D_{I V}: \text { The absolute value of the difference } \\
\text { between index value of target and } \\
\text { alternative case, namely the } \\
\text { Euclidean distance } \\
n: \text { The base for log transposition }\end{array}$} & 1 \\
\hline Algorithm 2 & $\begin{array}{c}D_{I V}=\left|I V_{T}-I V_{R}\right| \\
I S=\left(1-\frac{D_{I V}-M I N\left(D_{I V}\right)}{\operatorname{MAX}\left(D_{I V}\right)-M I N\left(D_{I V}\right)}\right) \times 100\end{array}$ & & $\begin{array}{c}3,4,5,6 \\
7,8,9,11,12,13,14\end{array}$ \\
\hline Algorithm 3 & $\begin{array}{c}D_{I V}=\left|\log _{n} I V_{T}-\log _{n} I V_{R}\right| \\
I S=\left(1-\frac{D_{I V}-M I N\left(D_{I V}\right)}{M A X\left(D_{I V}\right)-M I N\left(D_{I V}\right)}\right) \times 100\end{array}$ & & 2 \\
\hline
\end{tabular}

In order to verify the effectiveness of the improved continuous variable interpolation scoring system (Algorithm 3), this algorithm is used to give an example of this study to be compared with the classical interpolation algorithm.

Of the 34 cases that are put into the case library, the amount of investment ranges from RMB 0.015 billion to 90 billion. Compared with the continuous variables measured by the 5-point Likert scale, this variance is too large. The verification of the Nanjing HF project (project investment of 5 billion RMB Yuan) was used as a target case. When using the traditional interpolation scoring algorithm, if $I V_{R}=400$, then $I S=59.42 \%$; if $I V_{R}=2$, then $I S=95.30 \%$. When using the improved interpolation scoring algorithm, it is more appropriate to let $n=2$ according to the experts' opinion in combination with the range of variable variation. If $I V_{R}=400$, then $I S=66.33 \%$; if $I V_{R}=2$, then $I S=46.06 \%$. When the traditional interpolation scoring algorithm was adopted, the project with an investment of 5 billion RMB Yuan and the project with 200 million RMB Yuan were considered almost identical in scale, which obviously is not correct. It is evident that the improved interpolation scoring algorithm is more reasonable and can more accurately reflect the similarity of different construction projects in the dimension of the project scale. Thus, the improved interpolation scoring algorithm is used in this research.

\subsection{Case Reuse}

After calculating the similarity between the target case and candidate cases in the case library, the CBR decision system generates an output number of alternative cases that are similar to the target case for reference. The main contents of the output include (1) the name and quantity of similar cases; (2) the basic information and contact information of case data providers; (3) the project transaction modes of similar cases; and (4) performance data of similar cases.

\subsubsection{Algorithm for Determining the Number of Cases}

The CBR method in the literature [29] is adopted in this research. Considering the effectiveness of selected cases and ensuring a certain number of output cases, three-level restriction conditions are added as screening criteria for candidate cases:

$$
\begin{gathered}
C S>\operatorname{MAX}\left(60, \frac{1}{m} \sum_{1}^{m} C S_{i}\right) \\
N \geq 3 \\
C S_{i}-C S_{i+1}<\frac{1}{m} \sum_{1}^{m}\left(C S_{i}-C S_{i+1}\right)
\end{gathered}
$$

In Equations (1)-(3), CS is the similarity value between the candidate case and the target case, and it is arranged in descending order; and $N$ is the number of output cases; $i=1,2, \ldots m$, where $m$ is the total number of cases in the case library. The similarity value between the output case and the 
target case must be greater than 60 , and also greater than the average similarity value. The number of output cases must be greater than 3 . Under the premise of the first two conditions, the similarity difference between the two adjacent cases descending by similarity value is guaranteed to be smaller than the average similarity difference in the previous $i$ cases.

\subsubsection{Project Transaction Modes of Similar Cases}

The random combination of four sub-modules can generate at least 180 potential alternative cases. However, the internal logic between sub-modules determines that the number of practical transaction mode system is much lower. The CBR decision system can be applied for reference and learning of practical project transaction modes; namely, one output alternative case generates one project transaction mode, which can significantly reduce the number of alternative cases and improve the decision-making efficiency. In addition, large-scale construction projects tend to have a huge contract system which includes different types of contract, and then corresponding procurement methods will vary with the contract terms and other factors. Even within the same contract type, the payment condition and payment method can vary. Therefore, although the general information of the transaction mode of construction projects can be easily obtained, it is worthwhile to collect more information about details of the transaction mode for each project through interviews to make further design decisions.

\subsection{Case Revision}

Case revision means the retrieved solutions are revised or redesigned based on the needs of the new situation. Case revision mainly includes two types: manual revision and automatic revision. Considering the complexity of the design work for project transaction modes and the difficulty of constructing the case revision rule set, this paper mainly adopts a manual revision strategy considering three aspects: the owner's preference for a transaction mode, extreme value, and secondary learning.

\subsubsection{Owner's Preference for a Transaction Mode}

The questionnaire respondents take different roles in each case project, and the "owner" in the "owner's preference for a transaction mode" is not a separated individual but a group or company; therefore, "preference" is the preference of this group. However, there will be certain differences within the group. If the group preference is reflected by an individual in the group or individual's guess about the group, we believe that this is not a good move. Furthermore, the transaction mode is a discrete variable, which emphasizes selection or design rather than a degree. Therefore, in the previous article, we made the assumption of neutral preference. Here, we also need to revise the output project transaction mode according to the preference of the target case's owner. This is not to emphasize the "owner's preference for transaction mode" on the design of the project transaction mode too much. Two main considerations are as follows: firstly, factors that affect the transaction mode of construction projects are used as a similarity indicator system. Therefore, from the perspective of completeness and science, we should take this into account. Secondly, the owner's preference modification is based on the output of the alternative case transaction mode system. With other conditions unchanged, if the owner only considers that the performance has reached a certain standard, the owner can choose the preferred alternative.

\subsubsection{Extreme Value}

The selection of alternative cases with the final composite similarity value ignores the influence of the extreme value of the influence factors on the choice of project transaction mode. Taking the "inter-subject interference level" as an example, if the comprehensive evaluation of the "inter-subject interference level" of the alternative case is 3 points, the influence level among the sub-items of the alternative case is medium, and both DBB and DB methods are applicable to this project. However, the comprehensive evaluation of the target case is 5 points, indicating that the sub-items of the target 
case interfere with each other and have a certain influence on each other. In this situation, DB is more suitable for the target case. Theoretically, DB should be applied in the target case in the absence of other extreme factors. When multiple extreme values exist, it is necessary to match each extreme value with the project transaction mode. Otherwise, the project transaction mode redesign is needed.

\subsubsection{Secondary Learning}

The case data collected by questionnaires are limited, and the learning from alternative cases is preliminary. Therefore, the decision-making is focused more on choice than design. Therefore, the questionnaire needs to fill in "individual e-mail" to provide a method for the second study of the case. When owners of the target case design the project transaction mode, they can ask consultants for advice, which also promotes the transfer of construction knowledge within the industry.

\subsection{Performance Prediction}

Different owners have different performance requirements for various dimensions of the project. This research selects four dimensions of performance: schedule, cost, quality, and safety, which are the most important indicators that the academic community and the industry care about $[34,35]$. The performance prediction of other dimensions is placed in the secondary learning correction.

Performance prediction is based primarily on performance data from the collected cases and the owner's requirements for different dimensions of performance. Performance prediction mainly includes performance prediction for each dimension and comprehensive performance prediction. The similarity value between the target case and candidate cases were normalized, and then the weights are used to predict the performance of each dimension for the target project case. The comprehensive performance of the construction project consists of the performance of each dimension, and the weight of each dimension needs to be allocated according to the owner's requirements for project performance. A survey can be conducted in the owner group, and AHP can be used to derive the weight of different dimensions of performance to predict the comprehensive performance of the target case. The specific calculation process for performance prediction is as follows:

$$
\begin{gathered}
W V_{i}=\frac{C S_{i}}{\sum_{1}^{N} C S_{i}} \\
S P_{T}=\sum_{i}^{N} W V_{i} \times S P_{i} \\
C P_{T}=\sum_{i}^{N} W V_{i} \times C P_{i} \\
Q P_{T}=\sum_{i}^{N} W V_{i} \times Q P_{i} \\
S a P_{T}=\sum_{i}^{N} W V_{i} \times S a P_{i} \\
C o P_{T}=W_{S} \times S P_{T}+W_{C} \times C P_{T}+W_{Q} \times Q P_{T}+W_{S a} \times S a P_{T}+\sum_{1}^{m} W_{j} \times O P_{j} \\
W_{S}+W_{C}+W_{Q}+W_{S a}+\sum_{1}^{m} W_{j}=1
\end{gathered}
$$

In Equations (4)-(10), $C S_{i}$ represents the similarity between candidate case $i$ and the target case; $N$ represents the number of candidate cases; $W V_{i}$ represents normalized similarity value; $S P i, C P i$, $\mathrm{QPi}, \mathrm{SaPi}, \mathrm{OPi}$ represents schedule performance, cost performance, quality performance, safety performance, and the other performance parameters of candidate case $i$, respectively; $S P_{T}, C P_{T}, Q P_{T}$, $\mathrm{SaP}_{T}, O P_{j}$ represent the predicted schedule performance, cost performance, quality performance, safety performance, and other performances of the target case, respectively; $W_{S}, W_{C}, W_{Q}, W_{S a}, W_{j}$ represent owners' requirements for schedule, cost, quality, safety, and other dimensions, respectively; and $C_{o} P_{T}$ represents predicted comprehensive performance. 
According to the actual situation, sometimes some simplified methods may be used for performance prediction; for example, we may use the weighted average value of the similar cases as the predicted performance of the target case.

\section{Model Verification}

Verification testing was implemented to verify the effectiveness of the CBR design method developed in this research. Based on the above-proposed criteria, a total of 34 construction project cases were selected and put into use in the case library for this research. Each case in the case library was selected as a target case, and the other remaining cases were used as alternative cases. The similarities (project transaction mode, performance evaluation) between the target case and output case generated by the CBR design method are compared to verify the effectiveness of the method. One of these cases, the Nanjing HF project, is selected to explain the details of the verification process further.

\subsection{Data Collection}

Cases of this study are mainly obtained through the following approaches: firstly, in the past project research process, we accumulated relevant data on some projects. According to the data required for the research, we have supplemented this part of the case data. Secondly, we contacted alumni working in the construction industry through Hohai Alumni Association, and they provided us with some cases. Thirdly, we searched for articles regarding companies within the 2016 China Top 50 general contracting enterprises; then, we sent the questionnaires to the corresponding authors of these articles. The survey lasted for nine months from April 2017 to December 2017. In the first month, small-scale survey distribution and collection was conducted to get feedback and improve this questionnaire. After the questionnaire was adjusted, the survey was distributed and completed through both online and in-person on-site visits. Three hundred questionnaires were sent out, and 103 were collected, with a collection rate of $34.33 \%$. Among all 103 collected questionnaires, 83 questionnaires were valid excluding questionnaires with missing data, with an effective recovery rate of $80.58 \%$. The questionnaire is based on the last completed project that the survey respondents participated in. In fact, before the questionnaire was issued, we tried to find the person most familiar with a project to ensure the quality of the data collected by questionnaire. Therefore, 83 questionnaires corresponded to 83 different projects. The content is divided into four parts: the first part is the background of the survey respondents, the second part is the main attributes of the case project, the third part is the quantitative descriptions about the influence factor value of transaction mode in case project, and the fourth part is the performance data of the case project. The third part and the fourth part were mainly discussion questions.

\subsection{Data Pre-Processing}

Most of the survey respondents had a good academic background and practical experience in construction engineering and management. The education level and working years of the respondents are shown in Tables 2 and 3, respectively.

Table 2. Education level of respondents.

\begin{tabular}{cc}
\hline Education Level & Number \\
\hline Specialties and below & 2 \\
Bachelor & 44 \\
Master & 37 \\
Total & 83 \\
\hline
\end{tabular}


Table 3. Working years of respondents.

\begin{tabular}{cc}
\hline Working Years & Number \\
\hline Less than 5 years & 31 \\
5-10 years & 28 \\
10-20 years & 19 \\
More than 20 years & 5 \\
Total & 83 \\
\hline
\end{tabular}

In the survey of project performance, the five-point Likert scale is used in the questionnaire to quantify each influence factor's value of the project transaction mode. The respondents made ratings ( 1 to 5 ) on the five dimensions of performance for each project. It should be pointed out that the performance here is the perceived performance of the interviewee on the project. A higher score means the project achieved better performance in this dimension.

\subsection{Selection of Similar Cases}

Based on the requirements of the similarity index system above, the index data of the HF projects are input into the CBR system. Through the corresponding similarity algorithm, the similarity values of each candidate case in the case library are calculated and sorted in descending order, as drawn in Figure 4. Based on calculation using Equations (6)-(8), the number of output cases is determined to be 4: namely the Frontier Industrial Park (phase 1) project in Shiping Zone, Chongqing (84.5\%), the Taiping Road project in Kunming (80.95\%), the S55 Xuantong Expressway in Xuancheng $(78.74 \%)$, and the rapid transformation of Weiyi Road in Nanjing (76.54\%). These four cases are the key reference cases for designing the target case's transaction mode. Compared with the other three projects, only the Shiping Area Frontier Industrial Park (Phase 1) project and target case belong to the same type of construction project (house building project), which makes it more meaningful for selection as the reference case.

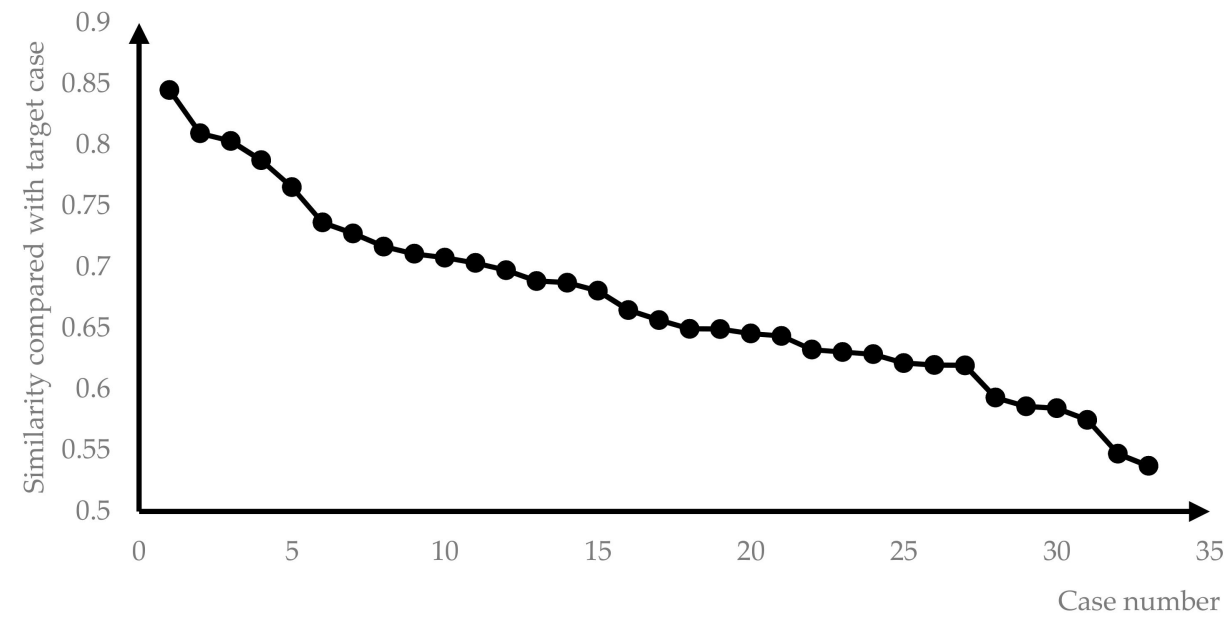

Figure 4. Nanjing HF similarity value ranking chart.

\subsection{Comparison of Project Transaction Mode and Performance Evaluation}

\subsubsection{Comparison of Project Transaction Mode}

The transaction mode adopted by the target case and the output of four cases are shown in Table 4 . 
Table 4. Project transaction modes of target case and alternative cases.

\begin{tabular}{ccccc}
\hline Project Name & $\begin{array}{c}\text { Project } \\
\text { Delivery Method }\end{array}$ & Contract Type & $\begin{array}{c}\text { Owner's } \\
\text { Management Method }\end{array}$ & $\begin{array}{c}\text { Project } \\
\text { Procurement Method }\end{array}$ \\
\hline Nanjing HF & DBB & Unit price contract & Self-management method & Open bidding \\
Frontier Industrial Park & EPC & Unit price contract & Self-management method & Open bidding \\
in Chongqing & PPP & Unit price contract & Self-management method & Invited bidding \\
Taiping Road in Kunming & DB & Unit price contract & Self-management method & Open bidding \\
S55 Xuantong Expressway & BT & Unit price contract & Self-management method & Open bidding \\
Weiyi Road in Nanjing & & & &
\end{tabular}

In terms of the project delivery method, the four output cases generated by the CBR decision-making system showed variance. The four output cases adopted four different project delivery methods, including EPC, DB, BOT and BT. A two-step case revision process was performed to improve the original method. In the first step, the revision of the owner's preference for the project delivery method is added. HF project is a real estate project developed by Power China Real Estate Group Ltd. in Nanjing. Due to the characteristics of real estate development projects, including a small number of house types, mature practices and the pursuit of low development cost, real estate project developers (owners) who possess strong capabilities of construction project management tend to prefer separating design and construction (DBB method) in order to strengthen their own control during the whole project process. This statement can be verified by the fact that the DBB method was adopted by all seven real estate projects that were selected in the case library. In the second step, the revision of extreme value is added. The target case scored 5 points in the "degree of influence of policies and regulations when selecting project transaction mode", and the Frontier Industrial Park (Phase 1) project in Chongqing reached 4 points, and the rest of the cases were less than or equal to 3 points, which indicated that the target project transaction mode was designed with more consideration of adapting to local policies and regulations.

Although the four cases showed significant variance on the project delivery method, high-level consistency was found among these four cases regarding contract type, owner's management method, and project procurement method. The owners of the four projects all selected the unit price contract and self-management method, indicating that the owners possess certain construction project management capabilities or have the goal of strengthening their self-management capability. This type of owner is usually more likely to take the risks of a unit price contract to better achieve the performance goals of the construction project through their own management. In terms of the project procurement method, except for the invited tendering used in the Taiping Road Project in Kunming, the open tendering method is adopted in all other projects. Due to the mandatory requirements of the bidding and tendering law, most domestic construction projects adopt the open tendering method. The Taiping Road project in Kunming was operated in the BOT method. Currently, BOT has not developed widely in China, and only a small number of companies have the capability to operate construction projects in the BOT mode. Therefore, the invited tendering method is adopted in the Taiping Road project in Kunming instead of the open tendering method.

\subsubsection{Comparison of Performance Evaluation}

By normalizing the output of the four cases' similarity values, the weights of each case are obtained, by which the performance values of each dimension of the target case can be predicted. With respect to the comprehensive performance evaluation, the original method suggested the implementation of demand surveys among owners' groups and using the AHP method to derive weights for more dimensional performance. In this paper, the average arithmetic method is used for prediction. As shown in Table 5, the predicted value of target case performance basically reflects actual performance, but there is a big difference in safety performance, which is related to various factors such as different investments in safety and the objective attitudes of management personnel on safety management. Due to a large number of influencing factors of project performance, the performance prediction here cannot be very accurate. As far as the survey conducted in this study is concerned, 
only $41.96 \%$ of cases have a comprehensive performance of 3.75 points, indicating that the performance of most of the cases is low.

Table 5. Comparison of forecasting and actual performance.

\begin{tabular}{ccccccc}
\hline Project Performance & Time & Cost & Quality & Safety & Similarity & $\begin{array}{c}\text { Comprehensive } \\
\text { Performance }\end{array}$ \\
\hline Frontier industrial park & 3 & 4 & 4 & 5 & $84.5 \%$ & 4 \\
in Chongqing & 4 & 3 & 4 & 4 & $80.95 \%$ & 3.75 \\
Taiping Road in Kunming & 4 & 4 & 3 & 4 & $78.74 \%$ & 3.75 \\
S55 Xuantong Expressway & 4 & 4 & 4 & 4 & $76.54 \%$ & 4 \\
Weiyi Road in Nanjing & 3.74 & 3.75 & 3.75 & 4.26 & - & 3.875 \\
Forecasting performance & 4 & 4 & 4 & 3 & - & 3.75 \\
Actual performance & & & & & & \\
\hline
\end{tabular}

\section{Conclusions}

Real practice and working experience play significant roles in the construction industry. The accumulation of experience provides ideas and references for solving new problems. The decision-making for project transaction modes is not just a simple question of choice but a comprehensive design optimization problem considering both theory and the real situation. In practice, it is beneficial for managers and engineers to learn from past excellent project cases and innovate the transaction mode based on the characteristics of the project itself. In this way, the optimal design of the project transaction mode can be implemented successfully to achieve the project objectives.

This paper proposed an innovative project transaction mode design method for construction projects based on an improved case-based reasoning method. Firstly, past excellent project cases were selected to build a case library and stored in a structured way. Secondly, a similarity index system was established based on the influence factors of project transaction mode for case retrieval. Thirdly, the similarity index calculation algorithm generated a certain number of reference cases as output. In the fourth step, the target case's transaction mode was revised and redesigned through modification for the owner's preference for project transaction modes, extreme values correction, and secondary learning correction. In the last step, the performance of the target case was predicted based on the reference case. Since this case-based reasoning system can be used to predict the performance of a construction project, the transaction mode of the project can be designed to guarantee the high performance of the project. At the same time, the secondary learning correction in the method strengthens the optimization of the transaction mode design and also promotes the transfer of construction management knowledge within the construction industry. Moreover, since the CBR method is a well-developed methodology that does not require too large of a computation, the newly developed method has good potential to be implemented in other construction projects and promote development for the construction management industry.

Since the Chinese construction market is closer to the buyer's market, the users of this method are mainly buyers: namely, project owners. However, this study adopts the perspective of the transaction and tries to study the complete transaction process from a relatively neutral position. Therefore, it also has specific reference significance for the contractor. How should this method be applied in practice? The owner may need to complete the following work step by step: firstly, collect data on the construction case of owners' industry, mainly including transaction mode information and performance information; secondly, screen out a certain amount of learning cases according to the criteria provided in this study; thirdly, study the cases to be referenced in depth, and invite participants to jointly modify and further design the transaction mode of the project.

This study also has certain shortcomings which need to be improved. Because the current collection of construction cases in China is difficult, the number of cases collected is small, and cases averaging comprehensive performance are even fewer. Therefore, when applying this method to making decisions, the results may have inherent bias. As the number of follow-up cases increases, decisions made by this method will be continually improved, which will gradually overcome such 
shortcomings and improve project sustainability. Besides this, the project performance mentioned in the article is perceived performance, and different roles in the project will have different understandings of this, which may lead to the overestimation or underestimation of performance. Furthermore, the model verification done in the text is more verification rather than validation. More cases are needed to verify the validation of this model. However, in general, it still has a certain reference value for the scientific decisions of project transaction modes.

For the future work of this study, the following suggestions can be adopted. Firstly, the differences between construction projects in various industries should be taken into consideration. Secondly, more high-quality cases can be added into the case library to enrich its contents further. Thirdly, the performance forecasting method proposed in this paper can be further improved. In the end, the same idea of the "secondary learning" step developed in this paper can also be used to establish an "expert tank" for construction project transaction mode design. In this way, more professional advice and suggestions can be gained from experts with rich practical experience during the transaction mode design process for construction projects.

Author Contributions: Conceptualization, J.D. and J.J.; Methodology, J.J. and C.J.; Validation, J.J. and J.D.; Formal Analysis, J.J. and J.D.; Investigation, J.D., J.J. and N.W.; Writing-Original Draft Preparation, J.J. and J.D.; Writing-Review and Editing, C.J. and N.W.; Supervision, J.D. and C.J.; Funding Acquisition, J.D.

Funding: This research was funded by the National Natural Science Foundation of China (grant number 71402045) and the Fundamental Research Funds for the Central Universities (Project No. 2017B18114).

Acknowledgments: The authors wish to acknowledge the supports from the responders of the questionnaires.

Conflicts of Interest: The authors declare no conflict of interest.

\section{References}

1. ASCE. Quality in the Constructed Project: A Guide for Owners, Designers and Contractors, 2nd ed.; American Society of Civil Engineers: Reston, VR, USA, 2000.

2. Ding, X.; Sheng, Z.H.; Du, J.G.; Li, Q. Computational Experiment Study on Selection Mechanism of Project Delivery Method Based on Complex Factors. Math. Probl. Eng. 2014, 2014, 1-8. [CrossRef]

3. Liu, B.S.; Huo, T.F.; Liang, Y.; Sun, Y.; Hu, X. Key Factors of Project characteristics Affecting Project Delivery System Decision Making in the Chinese Construction Industry: Case Study Using Chinese Data Based on Rough Set Theory. J. Prof. Issues Eng. Educ. Pract. 2016, 142, 1-12. [CrossRef]

4. Shane, J.; Bogus, S.; Molenaar, K. Municipal water/wastewater project delivery performance comparison. J. Manag. Eng. 2013, 29, 251-258. [CrossRef]

5. Chen, Y.Q.; Zhang, N.; Yang, Q.B. Literature Review on Project Delivery Systems. J. Eng. Manag. 2010, 24, 473-478.

6. Alhazmi, T.; McCaffer, R. Project procurement system selection model. J. Constr. Eng. Manag. 2000, 126, 176-184. [CrossRef]

7. Mafakheri, F.; Dai, L.M.; Slezak, D.; Nasiri, F. Project delivery system selection under uncertainty: Multicriteria multilevel decision aid model. J. Manag. Eng. 2007, 23, 200-206. [CrossRef]

8. Khanzadi, M.; Nasirzadeh, F.; Hassani, S.M.; Su, Q. An integrated fuzzy multi-criteria group decision making approach for project delivery system selection. Sci. Iran. 2016, 23, 802-814. [CrossRef]

9. Teak, H.C. A method of selecting delivery systems for public construction projects using the analytic network process. J. Arch. Inst. Korea Struct. Constr. 2003, 19, 211-218.

10. Lu, Y.Q.; Zhang, H.Q. Selecting the Appropriate Project Delivery System Using Improved ANP. J. Eng. Manag. 2013, 27, 29-33.

11. Ling, F.Y.Y.; Liu, M. Using neural network to predict performance of design-build projects in Singapore. Build. Environ. 2004, 39, 1263-1274. [CrossRef]

12. Chen, Y.Q.; Liu, J.Y.; Li, B.G.; Lin, B. Project delivery system selection of construction projects in China. Experts Syst. Appl. 2011, 38, 5456-5462. [CrossRef]

13. Touran, A.; Gransberg, D.D.; Molenaar, K.R.; Ghavamifar, K. Selection of Project Delivery Method in transit: Drivers and Objectives. J. Manag. Eng. 2011, 27, 21-27. [CrossRef] 
14. Abkarian, H.; El Asmar, M.; Underwood, S. Impact of Alternative Project Delivery Systems on the International Roughness Index Case Studies of Transportation Projects in the Western United States. Transp. Res. Rec. 2017, 2630, 76-84. [CrossRef]

15. Luo, S.Z.; Cheng, P.F.; Wang, J.Q.; Huang, Y. Selecting Project Delivery Systems Based on Simplified Neutrosophic Linguistic Preference Relations. Symmetry 2017, 9, 151. [CrossRef]

16. Ribeiro, F.L. Project delivery system selection: A case-based reasoning framework. Logist. Inf. Manag. 2001, 14, 367-375. [CrossRef]

17. Luu, D.T.; Ng, S.T.; Chen, S.E.; Jefferies, M. A strategy for evaluating fuzzy case-based construction procurement selection system. Adv. Eng. Softw. 2006, 37, 159-171. [CrossRef]

18. Yousang, Y.; Jinho, J.; Changtaek, H. Decision-making Support Systems Using Case-based Reasoning for Construction Project Delivery Method Selection: Focused on the Road Construction Projects in Korea. Open Civ. Eng. J. 2016, 10, 500-512.

19. Meng, F.S. A Study on Project Delivery System Selection Based on Relational Case Based Reasoning Theory; Tianjin University: Tianjin, China, 2011.

20. Ding, J.Y.; Wang, Z.F.; An, X.W. Research on the Innovation of Design-Build Transaction Mode of Water Conservancy and Hydropower Project; China Building Industry Press: Beijing, China, 2017.

21. Ding, J.Y.; Jia, J.Y.; Hu, L.C.; Wang, N. Design Path of Construction Project Transaction Mode based on Value-added Analysis of Project Objectives. J. Eng. Stud. 2017, 9, 482-489.

22. Pietroforte, R.; Miller, J.B. Procurement methods for US infrastructure historical perspective and recent trends. Build. Res. Inf. 2002, 30, 425-434. [CrossRef]

23. Konchar, M.; Sanvido, V. Comparison of US project delivery systems. J. Constr. Eng. Manag. 1998, 124, 435-444. [CrossRef]

24. Love, M.; Skitmore, G.; Earl, P.E.D. Selecting a suitable procurement method for a building project. Constr. Manag. Econ. 1998, 16, 221-233. [CrossRef]

25. Rojas, R.M.; Kell, I. Comparative analysis of project delivery systems cost performance in Pacific Northwest public schools. J. Constr. Eng. Manag. 2008, 134, 387-397. [CrossRef]

26. Carpenter, N.; Bausman, D.C. Project Delivery Method Performance for Public School Construction: Design-Bid-Build versus CM at Risk. J. Constr. Eng. Manag. 2016, 142. [CrossRef]

27. Shrestha, P.P.; Fernane, J.D. Performance of Design-Build and Design-Bid-Build Projects for Public Universities. J. Constr. Eng. Manag. 2017, 143, 75-83. [CrossRef]

28. Minchin, R.E.J.; Li, X.X.; Issa, R.R.; Vargas, G.G. Comparison of Cost and Time Performance of Design-Build and Design-Bid-Build Delivery Systems in Florida. J. Constr. Eng. Manag. 2013, 139. [CrossRef]

29. Park, J.; Kwak, Y.H. Design-Bid-Build (DBB) vs. Design-Build (DB) in the US public transportation projects: The choice and consequences. Int. J. Proj. Manag. 2017, 35, 280-295. [CrossRef]

30. Shrestha, P.P.; O'Connor, J.T.; Gibson, G.E.J. Performance Comparison of Large Design-Build and Design-Bid-Build Highway Projects. J. Constr. Eng. Manag. 2012, 138, 1-13. [CrossRef]

31. Tran, D.; Lampe, J.C.; Bypaneni, S.; Molenaar, K.R. An Empirical Comparison of Cost Growth between Highway Design-Bid-Build and Design-Build Projects by Project Size. Constr. Res. Congr. 2016. [CrossRef]

32. Hale, D.R.; Shrestha, P.P.; Gibson, G.E.R.; Migliaccio, G.C. Empirical Comparison of Design/Build and Design/Bid/Build Project Delivery Methods. J. Constr. Eng. Manag. 2009, 135, 579-587. [CrossRef]

33. Park, H.S.; Lee, D.; Kim, S.; Kim, J.-L. Comparing Project Performance of Design-Build and Design-Bid-Build Methods for Large-sized Public Apartment Housing Projects in Korea. J. Asian Arch. Build. Eng. 2015, 14, 323-330. [CrossRef]

34. Sullivan, J.; El, A.S.; Chalhoub, J.; Obeid, H. Two Decades of Performance Comparisons for Design-Build, Construction Manager at Risk, and Design-Bid-Build: Quantitative Analysis of the State of Knowledge on Project Cost, Schedule, and Quality. J. Constr. Eng. Manag. 2017, 142. [CrossRef]

35. Love, P.E.D. Influence of project type and costs in building procurement method on rework construction projects. J. Constr. Eng. Manag. 2002, 128, 18-29. [CrossRef]

36. Tran, D.Q.; Diraviam, G.; Minchin, R.E.J. Performance of Highway Design-Bid-Build and Design-Build Projects by Work Types. J. Constr. Eng. Manag. 2018, 144. [CrossRef]

37. Seob, L.Y.; Hwang, B.-G. Impacts of Contract types on Construction Project Performance- Cost Reimbursable and Lump Sum. Korean J. Constr. Eng. Manag. 2007, 8, 155-163. 
38. Xu, J.; Chi, L. Discussion on transaction cost based on characteristics of contacts and theories of transaction cost. Constr. Manag. Mod. 2009, 23, 522-526.

39. Wang, Z.F.; Chen, L.; Chen, S. Economic Analysis of Owner's Management Approach in Project Transaction. Soft Sci. 2008, 22, 9-11.

40. Dong, L.; Zhou, J. Owners' Role and Participation in Construction Safety Management. In Proceedings of the IEEE International Conference on Electronics, Communications and Control (ICECC), Ningbo, China, 9-11 September 2011.

41. Chen, Y.Q.; Jiao, S.J. Influence of project delivery system and payment method on project cost performance. J. Tongji Univ. 2011, 39, 1407-1412.

42. Waston, I. Case-based reasoning is a methodology not a technology. Knowl.-Based Syst. 1999, 12, $303-308$.

43. Dikmen, I.; Birgonul, M.T.; Gur, A.K. A case-based decision support tool for bid mark-up estimation of international construction projects. Autom. Constr. 2007, 17, 30-44. [CrossRef]

44. De Soto, B.G.; Adey, B.T. Investigation of the case-based reasoning retrieval process to estimate resources in construction projects. Procedia Eng. 2015, 123, 169-181. [CrossRef]

45. Jin, R.; Han, S.; Hyun, C.; Cha, Y. Application of Case-Based Reasoning for Estimating Preliminary Duration of Building Projects. J. Constr. Eng. Manag. 2016, 142. [CrossRef]

46. Wu, H. A framework of combining case-based reasoning with a work breakdown structure for estimating the cost of online course production projects. Br. J. Educ. Technol. 2014, 45, 595-405.

47. Goh, Y.M.; Chua, D.K.H. Case-based reasoning for construction hazard identification: Case representation and retrieval. J. Constr. Eng. Manag. 2009, 135, 1181-1189. [CrossRef]

48. Bai, J.; Li, Y.Q.; Lu, Y.J.; Le, Y. An Approach to Forming Top Management Team of Mega Infrastructure Projects Based on Improved Case-Based Reasoning. J. Syst. Manag. 2016, 25, 181-272.

49. Riccardo, B.; Cristiana, L.; Gabetta, M.; Milani, G.; Nuzzo, A.; Favalli, V.; Arbustini, E. Translational Bioinformatics: Challenges and Opportunities for Case-Based Reasoning and Decision Support. ICCBR 2010, $6176,1-11$.

50. Lu, Y.; Wu, Y.Y.; Da, Q.L. A Sustainable Competitive Power Model of Enterprise Based on Case-based Reasoning. J. Ind. Eng. Eng. Manag. 2005, 19, 1-5.

51. Hashim, M.; Li, M.C.Y.; Yin, N.C.; Hooi, N.S.; Heng, S.M.; Yong, T.L. Factors influencing the selection of procurement systems by clients. In Proceedings of the International Conference on Construction Industry, Padang, Indonesia, 21-25 June 2006; pp. 1-6.

52. Cheung, S.O.; Suen, H.C.H.; Cheung, K.K.W. PPMS: A web-based construction project performance monitoring system. Autom. Constr. 2004, 13, 361-376. [CrossRef]

53. Yeung, J.F.Y.; Chan, A.P.C.; Chan, D.W.M. Developing a performance index for relationship-based construction projects in Australia: Delphi study. J. Manag. Eng. 2009, 25, 59-68. [CrossRef]

54. Wang, Z.F.; Yang, G.S.; Hong, W.M. Transaction Theory E Transaction Mode of Construction Projects; China Water Power Press: Beijing, China, 2010. 